\title{
Lease Maturity and Initial Rent: Is There a Term Structure for UK Commercial Property Leases?
}

\author{
Shaun A. Bond ${ }^{1}$, Pavlos Loizou and Patrick McAllister \\ University of Cambridge, CB Richard Ellis and University of Reading
}

June 2005

\begin{abstract}
This paper investigates the relationship between lease maturity and rent in commercial property. Over the last decade market-led changes to lease structures, the threat of government intervention and the associated emergence of the Codes of Practice for commercial leases have stimulated growing interest in pricing of commercial property leases. Seminal work by Grenadier (1995) derived a set of hypotheses about the pricing of different lease lengths in different market conditions. Whilst there is a compelling theoretical case for and a strong intuitive expectation of differential pricing of different lease maturities, to date the empirical evidence is inconclusive.

Two Swedish studies have found mixed results (Gunnelin and Soderbergh 2003 and Englund et al 2003). In only half the cases is the null hypothesis that lease length has no effect rejected. In the UK, Crosby et al (2003) report counterintuitive results. In some markets, they find that short lease terms are associated with low rents, whilst in others they are associated with high rents.

Drawing upon a substantial database of commercial lettings in central London (West End and City of London) over the last decade, we investigate the relationship between rent and lease maturity. In particular, we test whether a building quality variable omitted in previous studies provides empirical results that are more consistent with the theoretical and intuitive a priori expectations. It is found that initial leases rates are upward sloping with the lease term and that this relationship is constant over time.
\end{abstract}

Key words: term structure of leases, office rents, London

\footnotetext{
${ }^{1}$ Contact details: Shaun Bond, Department of Land Economy, University of Cambridge, 19 Silver Street, Cambridge, CB3 9EP. Email sab36@cam.ac.uk. Pavlos Loizou, CB Richard Ellis Ltd, Global Corporate Services, Kingsley House, Wimpole Street, London, W1G 0RE. Email pavlos.loizou@cbre.com. Patrick McAllister, Real Estate and Planning, The University of Reading Business School, PO Box 219, Whiteknights, Reading, RG6 6AW. Email p.m.mcallister@reading.ac.uk. The authors would like to thank Peter Damesick, Richard Holberton and Ian Kissane for providing helpful comments in addition to the data used in this study.
} 


\section{Introduction}

In the UK the dramatic changes to leasing patterns in the 1990s and the increase in the political salience of the subject has produced growing interest in lease pricing from real estate researchers. Researchers have proposed a range of models drawn from economic theory, most substantially from real options, to analyse lease pricing problems and offer optimal pricing solutions. However, despite the controversy surrounding the topic, there has been little empirical investigation of whether variation in lease terms produces variation in rents. In this paper, we use a sample of 935 London office leases granted between 1994 and 2004 to investigate the relationship between lease length and initial lease rates. Previous research (Soderberg and Gunnelin 2003 and Englund et al (2003) has found some evidence of a term structure in lease payments that varies over time.

For many UK property investors, government intervention in the commercial property leasing market has been perceived as a threat. Average lease lengths have been falling steadily throughout the last decade to produce a shift in the risk pendulum from tenants to landlords (ODPM, 2004). For landlords, shorter lease lengths are associated with decreases in income security. Shorter leases tend to produce increased possibilities of; voids and associated additional costs, falls in rent, negotiation weakness, additional exposure to risks associated with depreciation and repair and maintenance, potential changes to quality of tenant and new lease and consequent reduced liquidity. Consequently, the expected financial costs associated with potential letting termination are driven by the timing and probability of tenant vacation, the projected costs of a letting termination and the probability that the rent passing will exceed the Market Rent at the point of potential letting termination.

The positive value of an option to vacate will in most circumstances lie with tenants who benefit from increased flexibility in the management of their operational property holdings, the negotiating advantage associated with the ability to make the landlord incur costs associated with tenant vacation and the possibility of a downward adjustment of rent. From the tenant's perspective the main risks of long leases relate to the expected costs of exit. These will be determined by the actual costs of exit and the probability of an exit requirement. Such costs will be variable according to 
business sector, individual company and market conditions. Key factors will be fit outs costs, anticipated growth/contraction in the company, business structure of the company, the use in which the premises are put (core versus secondary) and rate of building and locational obsolescence and depreciation.

Further, in order to assess the tenant's position it is important to appreciate the available alternative options. In a long lease, these are to assign the lease, to sublet surplus space or to negotiate surrender with the landlord. The relative cost of 'exercising' these options is dependent upon market conditions at the point of desired termination of occupation. In 'hot' letting markets, it is reasonable to assume that there is a high probability that a lease can be assigned, surplus space can be sublet or that a landlord will accept a surrender payment. However, in a market downturn, the demand for premises will be lower with obvious consequences for the probability and costs of assignment/subletting and surrender.

This discussion begins to generate expectations about the pricing of leases in the commercial property market. We expect that leases which produce increased risks for investors should provide an increased return (higher rent). However, it is clear that at a given point in time expected risk will vary with systematic (expectations of future market conditions) and specific factors (quality of building/location, tenant quality). Indeed it is possible to envision circumstances where shorter leases would generate a reduced rent. For instance, where the investor expects a market recovery in future, has a poor quality tenant (who wishes to secure the location) occupying high quality space.

\section{Previous Research}

The most influential recent work on lease pricing is Grenadier's (1995) analysis of a whole range of lease options. Grenadier explores the analogy of different lease lengths being comparable to bonds with different maturities. He sets out to produce an equilibrium rent for any length of lease and a term structure of lease rates analogous to a term structure of interest rates. His approach is to set out the processes by which short-term rents are generated - in essence by interaction of the evolution (as a geometric Brownian motion) of supply, demand and asset values. It is assumed 
that the value of a service flow (rent) from a lease can be replicated by buying the asset and writing a European call option on the underlying asset. ${ }^{2}$ In simple terms, a lease can be represented as buying the property and agreeing that the seller has the right to reclaim the property at the end of the period of use. The seller would only reclaim the property if it had some positive value. Given the above, the value of the rent is the (equilibrium) value of the freehold interest less the value of a European call option exercisable at the end of the proposed lease period. Having established the value of the call option, the equilibrium long-term lease payment is an annual equivalent of the difference.

Using this model, Grenadier offers a set of hypotheses about the pattern of lease lengths in different market conditions. In the vein of the term structure of interest rates, he describes three possible term structure shapes - downward-sloping, upwardsloping and single-humped. It is hypothesised that a downward-sloping curve would be associated with a 'hot' market where there is a high ratio between capital values and construction costs. This creates an incentive to build and generates an expectation of an increase in supply with rents falling in the future. Given this expectation occupiers place higher values on short leases relative to long leases since they do not wish to be 'stuck with' a fixed rent in a falling market. Landlords, in turn, prefer longer leases where rental falls are expected and would rationally accept less rent relative to short leases. Conversely, in a 'cold' market, the curve is upward sloping. Occupiers expect a lack of new supply, in turn, creating an expectation of future rental increases and rationally pay more for long fixed rent terms. For intermediate cases, the term structure takes a single-humped shape, with no anticipated supply in the short term but a supply response expected in the medium term, occupiers pay more for protection against short term rises in rent but expect rents to fall in the medium term.

Although the model does not take into account transaction costs, vacancies/nonrenewals and taxes, there is a powerful message that short lease terms should not automatically produce higher rents. For fixed rent leases and for a short lease

\footnotetext{
${ }^{2}$ Essentially the occupier/investor can get identical value (compared to a lease) by buying the freehold interest in the asset today whilst simultaneously receiving the present value of the freehold interest at the end of hypothetical lease term.
} 
landlords will require different rents depending on their expectations of future market conditions. If they expect market conditions to improve in the future, they should regard short leases more favourably compared to an expectation of deteriorating market conditions. Grenadier's work revealed the optionality inherent in real estate interests and the key role of rental volatility and the model of behaviour in rents. However, it is based upon a hypothesis of landlord behaviour - the expectations hypothesis - that works well in explaining the term structure of interest rates. It is questionable, to say the least, whether this is an accurate representation of landlord behaviour.

Following Grenadier (1995), a number of researchers (Ambrose, Hendershott and Klosek, 2002, Booth and Walsh 2002, Hendershott and Ward, 2003 and Stanton and Wallace, 2004) utilize the concepts of market equilibrium relationships in the development of a model for pricing lease cash flows. The assumption of market equilibrium is important since

\footnotetext{
"The equilibrium context implies that in an efficient market, all leases with the same maturity should provide the same present value to the lessor, irrespective of whether the rental rate is fixed, fully variable or partially variable" (Ambrose et al, 2002, 35)
}

Typically drawing upon standard option pricing theory, they make a number of assumptions about risk free rates, drift coefficients (growth in rents), volatility and rental behaviour to devise hypothetical optimal pricing solutions.

Whilst the work cited above focuses on assets values to the investor, McCann and Ward (2004) examine the optimal lease length from the tenants' perspectives and question the applicability of a term structure. The premise is that from the tenant's point of view, the cost of space varies with the lease length quite independently from the term structure of rental rates so that the value of a lease to a tenant is not exogenously given. In other words, the standard assumption that landlords will extract the same value from the property regardless of leases structure is disputed. The occupancy value will therefore be a function of tenant-specific and market variables legal and search costs, relocation probability and costs, rent and repairing costs, 
opportunity costs and ability to assign. They develop a model which, given certain assumptions, prices the range of lease lengths for individual tenants. Their key conclusion is that there is a clientele effect that overlays the financial equivalence of different lease lengths. In essence, landlords should maximise returns by ensuring that the asset is leased to the tenant (segment) for whom it is the optimal lease. The real world observation is that clearly some tenants require long leases for the purposes of being able to recover their initial costs or because of the goodwill associated with the site; department stores and head offices of major companies tend to move infrequently, small companies may prefer, for business reasons, to take on short leases if they plan to expand or re-locate within their planning horizon. In these circumstances, business reasons dominate the term structure of rents and it is not possible to trade between different clienteles in the way associated with financial models of term structure and arbitrage.

Following Grenadier's (1995) suggestion that hypothetical pricing solutions should be compared with actual market rents, there has been work that has attempted to identify a term structure of lease rates. At the aggregate level, there are significant methodological issues in isolating the effects of lease terms on rents as researchers are faced with problems of trying to disentangle the effects on rents of tenant and building quality and market conditions from lease provisions. Typically this work has modelled observed rent as a function of a range of lease, market and property-specific factors. Typically empirical findings have been inconclusive.

In the US much of the work on rent determination has focussed on exploring the relationship between base and percentage rents in shopping malls (see Wheaton, 2000, Miceli and Sirmans, 1995, Ambrose, Hendershott and Klosek, 2002, Ward and Hendershott, 2003). However, Mooradian and Yang (2000) explicitly focused the lease pricing effects of ability to exit. They examined a sample of 311 leases sign by a single public corporation (an attractive tenant) between 1992 and 1994 - a period of weak economic performance and high vacancy rates. They attempt to isolate the significance of options to cancel the lease, downsize (decrease the amount of space occupied) and sublet. They find that the only variable that has significant effect on rent is the right to downsize. However, only $10 \%$ of leases had a downsize clause compared to $30 \%$ and $49 \%$ that had options to cancel the lease or sublet respectively. 
A possible explanation for the observation of a rental premium for this variable is that it was not typical market practice.

Overcoming the problems of potential sample bias inherent in studies based upon a single landlord or tenant, Stanton and Wallace (2004) compare and contrast modelled of spot leases rates with observed rents for 711 lease originated between 1987 and 1996. They derive implied structure of forward rents for a range of metropolitan areas as of September 1997. Whilst acknowledging a lack of precision for some of the model inputs they find term structures that are broadly consistent with the prior expectations. However, the 'predicted' rents are not consistent with observed rents implying mispricings in the market. With particular relevance to this study, they find that the length of the lease has a statistically positive effect on realised rent whilst credit worthy tenants and increased size of letting lead to significant reductions in rent.

Similarly two Swedish studies argued that previous studies fail to allow for possible variation in the term structure of lease length. Gunnelin and Soderbergh (2003) report that differences in lease terms have statistically significant effects on commercial rents in the Stockholm CBD for 7 out of 15 years between 1977 and 1991. Partially confirming the term structure of lease rates, they identify an upward sloping curve in the bullish 1980s and a downward sloping curve in the bearish 1990s. Englund et al (2003) find much more mixed results for more recent trends in three Swedish centres. In only half the cases is the null hypothesis that lease length has no effect rejected and there is typically an upward slope in the terms structure of lease rates. This was counterintuitive given the market conditions and it suggests that the research, hampered by a lack of variations in the lease structures, has struggled to cope with the problems of isolating the effects of lease terms on rents from the other variables.

This is the case with ODPM (2004) who, in similar work in the UK, report similar counterintuitive results. In some markets, they find that short lease terms are associated with low rents, whilst in others they are associated with high rents. It is difficult to assess whether this is due to genuine term structure effects. ODPM (2004) suggest two other possible explanations for the findings. First, the model is failing to account sufficiently for the effects of tenant quality and building/location 
characteristics relative to lease terms - an argument that would be consistent with the McCann and Ward paper. Second, and more interesting, is an implied behavioural explanation for the lack of an impact of lease terms on rent. Their interview survey of market participants found that in the process of rent negotiation, agreement on rent usually preceded agreement on detailed lease terms. This could be explained either by both parties have common views on the characteristics of the leases even before the terms were settled or that the bargaining structure was inefficient within the current institutional environment. Although there has been little explicit research on the potential of cognitive biases to affect lease prices, it is clear that this may be a fruitful area of investigation. Rental expectations are central to the issue of lease pricing. Behavioural finance, with its roots in the psychological study of human decision making, has found that individuals often do not process information efficiently when making judgements about complex problems. Consequently, judgement and decision-making can be distorted by apparent irrationality and bias.

In summary, there are grounds to expect that observed rents will be conditioned by the terms of occupation. Ceteris paribus, we should expect that variations in lease terms should produce variations in observed rents. Lease length, in particular, is regarded as an important determinant of the risk in the cash flows delivered by leased real estate assets. However, in addition to differences in risks among different assets and sectors, expectations about risks of future cash flows will vary over time. Analogous to bond markets, a priori, we should not expect to observe a static rental premium or discount across different sectors and over time.

\section{Estimating a Term Structure of Office Rents}

The empirical studies that are most relevant to this study are the papers of Gunnelin and Soderberg (2003) and Englund et al (2003). In the first paper the model used both linear and quadratic function forms to estimate the term structure relationship. The quadratic model used was specified as

$$
\ln \text { lease }_{i}=\alpha_{0}+\sum_{i=1}^{N} \beta_{i} \text { Fact }_{i}+\sum_{j=1}^{M} \delta_{j} D_{j}+\sum_{l=0}^{M+1} \gamma_{l} D_{l} \text { Term }_{i}+\sum_{l=0}^{M+1} \lambda_{l} D_{l} \text { Term }_{i}{ }^{2}+e_{i}
$$


where lease $_{i}$ is the rental payment for lease $i$, Fact $_{i}$ are characteristics of lease contract $i$ such as size, age of building, whether the lease is a renewal of a previous contract and the institutional owner of the property occupied in lease $i . D_{j}$ represents a dummy variable for the year in which the lease was originated and Term $_{i}$ is the length of the contractual obligation for lease $i$. The Parameters $\alpha_{0}, \beta_{i}, \gamma_{i}, \lambda_{i}$ are estimated using OLS.

Englund et al (2003) present a similar model, except no parametric form is placed on the relationship between lease rental and term. While this may have advantages in allowing a flexible functional relationship between rental and term to be estimated, it comes at the expense of an increased number of parameters requiring estimation. This is a particularly issue in this study as the term of the leases often reaches 25 years or more.

A major methodological issue not encountered in the studies just mentioned, but of high relevance to the present paper, is the treatment of option clauses, such as lease break and upward-only rent reviews. Stanton and Wallace (2004) provide an extensive discussion of these issues and recommend using options-based valuation of each lease clause. They construct a net present value for the cash flows from each lease and use this measure in estimating the term structure of lease payments ${ }^{3}$. In the present paper we adopt an empirical approach to this issue. Firstly, as the five year upward-only rent review is a common institutional feature of the London office market, it is assumed that any adjustment that would be made to the value of each lease would be common to all leases. Hence the relative lease payments are unlikely to be affected. Secondly, with regard to lease breaks, we consider alternative functional forms that take into consideration the possible impact of the break provision on the rental payment. These alternative functional forms are discussed in the next section.

Where information is provided on rent-free periods we calculate an effective lease cost which spreads the savings from the rent-free period over the term of the lease.

\footnotetext{
${ }^{3}$ Though it is noted that their model has very low explanatory power.
} 


\section{Data}

The primary dataset used in this study is based on information collected by CB Richard Ellis. This database consisted of 726 leases for the City of London office market and 394 leases for the West End market. Figure 1 in the appendix displays a map of the London office market showing the West End and City markets, in addition to other main submarkets. A possible limitation of the data available from CB Richard Ellis is that it consists of leases where the underlying occupied space is almost always greater than 10,000 square feet in size. At first this may seem a limitation however, it may provide a simple way to control for tenant quality. As we do not have information on tenant credit worthiness it is assumed that larger tenants are likely to be more credit worthy than occupiers with smaller space requirements.

To supplement the analysis and check that the results obtained are not biased due to the restricted nature of the leases in the database, we compared the results obtained from the models, with estimates obtained from using data from the Estates Gazette service. This dataset is larger than the CB Richard Ellis data and covers lease transactions of varying sizes and from more locations in London. However, information on lease breaks and rent-free periods is not as detailed as widely available and the quality of the information, which is input from a wide variety of sources, is more difficult to ascertain ${ }^{4}$.

After sorting the CBRE data and removing outlying observations or information from years in which there were few observations, the number of leases that remained in the data set was 935. These leases covered the period from 1994 to 2004. A summary of the characteristics of these leases is shown in Table 1.

The information in Table 1 provides a breakdown on the sample leases by area as well as reporting the aggregate totals. From the table it can be seen that the sample is dominated by lease contracts for office space in the City of London (595 as opposed to 340 from the West End). The initial rents are higher in the City, $£ 345.09$ per $\mathrm{m}^{2}$, compared to $£ 323.77$ per $\mathrm{m}^{2}$ in the West End. The average space covered by the lease 
contracts is also higher in the City $\left(3,506.95 \mathrm{~m}^{2}\right)$ than the West End $\left(2,355.17 \mathrm{~m}^{2}\right)$. The higher rents on leases for City properties may reflect the higher portion of Grade A properties in the sample (67\% for City and $46 \%$ for West End). In the current sample $24 \%$ of all leases in the City had break clauses reported (10\% for the West End) and the average length of time before the break could be exercised was 9.06 years $(8.71$ years for the West End). Average lease lengths were slightly shorter in the West End (13.28 years) compared to the City (14.47 years).

The fact that the sample only considers leases where the occupied area is greater than 10,000 square feet may explain the characteristics observed in the sample. Typically the stock of office space in the West End is older with smaller floor plates compared to office space in the City. Properties in the City tend to be more modern with larger capacity floor plates designed to appeal to large corporate occupiers from the financial services sector.

Table 2 shows the distribution of leases by lease length and year of origination. There are distinct peaks in the lease terms centred around the periods of 10, 15, 20 and 25 years. There are few leases in the sample less than 5 years in maturity. This stands in contrast to the data presented in Gunnelin and Soderberg (2003) where most of the leases had maturities of less than five years with very few observations above seven years. From the data presented in this table there is little evidence to suggest that lease lengths are falling in the London office market. However, this should be interpreted in light of the nature of the sample, which is limited to large office space requirements. In these instance occupiers are likely to prefer longer lease terms due to the high frictional costs of relocating large numbers of employees and fitting out the premises. A chart of the lease terms for the entire sample is shown in Figure 2.

\section{Results}

To estimate the term structure model we use a variation of model (1) based on the Gunnelin and Soderberg (2003) study. The first specification assumes a linear relationship between term length and initial rent.

\footnotetext{
${ }^{4}$ Of course, it is likely that many leases contained in the Estates Gazette data will be the same of those
} 


$$
\begin{aligned}
& \ln \text { lease }_{i}=\alpha_{0}+\sum_{j=1}^{M} \delta_{j} D_{j}+\beta_{1} \ln \left(\text { size }_{i}\right)+\beta_{2} \ln \left(b k_{i}\right)+\beta_{3} G r B_{i} \\
& +\beta_{4} G_{i} C_{i}+\beta_{5} \text { Loc }_{i}+\sum_{l=0}^{M} \gamma_{l} D_{l} \text { Term }_{i}+e_{i}
\end{aligned}
$$

where lease $_{i}$ is the initial real rental payment for lease $i$, Size $_{i}$ is the amount of space occupied, $b k_{i}$ is the length of the lease break provision if one is included in the lease, $G r B_{i}$ is a dummy variable for leases where the occupied space is in Grade B properties and similarly $\operatorname{GrC}_{i}$ is a dummy variable to denote the occupied space is in a Grade $\mathrm{C}$ property. $L o c_{i}$ is a location dummy variable which takes the value 1 for lease in the West End market. $D_{j}$ represents a dummy variable for the year in which the lease was originated and covers the years from 1995 to 2004. Term $i$ is the length of the contractual obligation for lease $i$. The multiplicative dummy variables $D_{j}$ cover the period from 1994 to 2004.

Note that in all cases the real rent is used as the dependent variable in the model. The real rental value is obtained by deflating the nominal rent value of each lease by the corresponding value of the implicit price deflator of domestic final demand in the same year.

An alternative specification suggested in Gunnelin and Soderberg (2003) is to allow a quadratic specification for the term structure relationship. Adding a term to equation (2) that is quadratic in the term structure provides a model of the form

$$
\begin{aligned}
& \ln \text { lease }_{i}=\alpha_{0}+\sum_{j=1}^{M} \delta_{j} D_{j}+\beta_{1} \ln \left(\text { size }_{i}\right)+\beta_{2} \ln \left(\text { bk }_{i}\right)+\beta_{3} \text { GrB }_{i} \\
& +\beta_{4} \text { GrC }_{i}+\beta_{5} \text { Loc }_{i}+\sum_{l=0}^{M} \gamma_{l} D_{l} \text { Term }_{i}+\sum_{l=0}^{M} \lambda_{l} D_{l} \text { Term }_{i}{ }^{2}+e_{i}
\end{aligned}
$$

where $\operatorname{Term}_{i}^{2}$ is the square of the length of lease $i$.

in the CBRE data set. 
The outcome from applying OLS to equations (2) and (3) are shown in Tables 3 and 4 respectively. All standard errors are calculated using White's heteroscedasticity consistent covariance estimates.

Table 3 reveals a number of interesting results. There appears to be a strong linear association between the term structure variable and initial lease rates. The interactive lease maturity variable is significant and position in each year except for 1996. This result is much stronger than that found in Gunnelin and Soderberg. The positive sign on this variable is counterintuitive as it suggests that occupiers pay a higher lease to have a longer term. Such a result appears to go against anecdotal evidence from market participants which suggest that lower initial lease rates may be obtained by taking a longer lease term.

The individual year dummy variables provide some indication of the changing market conditions in London. Incremental lease rates increased from 1996 to 2002 before falling sharply in 2003 and 2004. This does appear to be consistent with market evidence that the late 1990s and early part of this decade saw strong increases in rent due to the expansion in financial service and technology related employment. However, following the downturn in these sectors in 2001 the leasing market has been considerably weaker.

The coefficient for size is negatively signed as expected, indicating that occupiers taking larger amounts of space receive a lower initial rent that those with smaller space requirements. The signs of the dummy variables for grade of building and location are also as expected with occupiers in lower grade buildings paying lower initial rents than those in grade A space. Also occupiers in the West End pay higher rates per square meter than those in the City when all other factors are held constant.

Finally the coefficient on the break variable is significant and negative. This finding also seems unusual as it is usually perceived that break clauses provide advantages for tenants and negotiated as part of a rental agreement it is likely that a premium would be paid for this option. However, there is an expectation that the value of this option would fall as the time to expiry increases. We will return to this issue at a later point. 
The overall fit of the equation is satisfactory with an R2 of $45 \%$, which implies that just under half of the variation in initial lease rates is explained by equation (2). To assess whether the nature of the term structure variable is changing we test the hypothesis that the coefficients from TM94 to TM04 are all equal. The resulting F-test statistic is 0.773 , which implies the hypothesis cannot be rejected ${ }^{5}$. That is, there does not appear to be a changing pattern to the relationship between lease length and initial rent in the London office market.

Table 4 shows the results of estimating equation (4). The difference between this table and the previous is the inclusion of the square of the interactive lease term variables (shown as TM94_2 to TM04_2 in Table 4). Only two of the quadratic terms are significant in Table 4 (in 1999 and 2001). Interestingly, the sign of the squared terms from 2001 onwards are all negative whereas previously the squared terms were positive (though with little significance). The remaining variables are essentially unchanged with the exception of the year dummy variables. In this case the dummy variables now suggest that initial rental rates peaked in 1999 with large falls occurring in 2003 and 2004. However, as only the dummy variable for 1999 is significant this finding needs to be treated with caution.

The relationship between term and initial lease rates is explored further by considering the test of a null hypothesis of the equality of the interactive term structure variables in equation 4 . The joint null hypothesis that

$$
\begin{aligned}
& \gamma_{1}=\gamma_{2}=\ldots=\gamma_{11} \\
& \lambda_{1}=\lambda_{2}=\ldots=\lambda_{11}
\end{aligned}
$$

is evaluated. It is found that this null is not rejected ${ }^{6}$. Again this is evidence that the term structure of initial lease rates does not appear to be changing. As a final test we examine the hypothesis that the coefficients of the squared interactive lease term variables are jointly equal to 0 . The $\mathrm{F}$ statistic of 1.65 is rejected at the significance level of $10 \%$ but is not rejected at the $5 \%$ level $^{7}$.

\footnotetext{
${ }^{5} \mathrm{~F}(10,908)=0.773$, p-value $=0.66$

${ }^{6} \mathrm{~F}(20,897)=1.037, \mathrm{p}$-value $=0.414$.

${ }^{7} \mathrm{~F}(11,897)=1.651, \mathrm{p}$-value $=0.08$. Note that a test that all term structure variables are jointly equal to zero is rejected with $\mathrm{F}(22,897)=5.118$, p-value $=0.00$.
} 
In light of these hypothesis test findings we reparameterise the model to remove the interactive dummy variables for year of origination and term. These are replaced by variables for the lease term and lease term squared. The resulting model is shown in Table 5.

All parameters in this model are statistically significant at the $10 \%$ level with the exception of the dummy variables for origination years 1995 and 2004. The pattern of the dummy variable coefficients once again shows the increases in rent up to 2003 before falling quite sharply. The lease term and lease term squared variable are both statistically significant and confirm a quadratic relationship between (log) rents and lease length. The location and grade variables are all strongly significant and the lease break term is significant and negative.

Finally the limitation of the data set with regard to lease size if further considered. As there are few leases in the sample below five years we re-estimate the previous model after removing all leases below five years from the data set. The resulting estimates are shown in Table 6. The overall magnitude of the parameter estimates is broadly similar to Table 5. A notable difference is that the coefficient of the squared term variable is no longer significant.

The information in Tables 5 and 6 can be used to plot the term structure of (real) initial lease rates in the London office market. To draw the curve it is assumed that the current year is 2004, the representative office is taken to be in the City of London and has a floor area equal to the average size shown in Table $1(3,506.95 \mathrm{sq} \mathrm{m})$. The resulting curves are shown in Figure 3. In both cases an upward sloping curve linking initial lease rates to the term of the lease is observed.

Before concluding we provide a further discussion of the empirical treatment of lease breaks in the contacts. Two additional models were considered, one that removes all lease contracts with a break in the sample and another that treats lease break as being equal to the terminal maturity ${ }^{8}$.

\footnotetext{
${ }^{8}$ That is, we assume lease breaks are always exercised or at least used to renegotiate a new contract.
} 
It was found that when all leases with a break clause were removed from the sample and the model estimated using the remaining observations (615 remained), the parameter estimate were very similar to those obtained in Table 5 (results not reported). The sign of the lease length variable remained positive.

When the lease maturity was taken to be the minimum of either the lease break term or the lease term it was found that the term structure of initial lease rates was still upward sloping (results not reported). The signs of the term and term squared variable were reversed but this simply meant that the initial lease rates grew rapidly once lease terms reached above 20 years. The explanatory power of this model was also lower than the other equations estimated.

As a final check on the robustness of the results we applied the equations (2) and (3) to an alternative lease data set obtained from the Estates Gazette. This contained a larger number of leases than the CBRE data and covered more regions within London. However, there were concerns about the reliability of the data which is why this dataset did not form the core data used in this study. When the models were estimated it was found that a similar upward sloping term structure in initial lease rates appeared. This confirms that the findings of this study are unlikely to be due to restricted nature of the lease data set ${ }^{9}$.

\section{Conclusion}

In this paper we have investigated the relationship between lease length and initial lease rates in the London office market. This follows earlier work by Gunnelin and Soderberg (2003) and Englund et al (2003). Data on 935 office leases, originated between 1994 and 2004, in the City of London and the West End were used to estimate models of initial lease rates holding constant for lease characteristics such as size, location, quality of building, year of origination, timing of lease breaks and lease term. While a term structure of initial lease rates was found, unlike the previous studies, it did not appear to change over time. There was also mixed evidence on whether a linear or quadratic form for the term structure was most appropriate.

\footnotetext{
${ }^{9}$ Results not reported but are available on request from the authors.
} 
A surprising result was that the term structure of initial lease rates was upward sloping in lease term. This implies that occupiers requiring longer leases pay higher initial rates than those requiring shorter leases. Such a finding appears at odds with market evidence of lease transactions and may reflect uncontrolled for factors relating to tenant quality (or credit rating), micro-location factors affecting rent for similar buildings and lease terms, the option-related elements of lease contracts (such as rent reviews) or possible unrecorded payments by landlords contributing to "fit-out" costs or other transaction-related incentives. This finding also held constant when the few shorter leases in the sample were removed on the model estimated only including leases greater than five year.

In order to control for lease breaks we adopted an empirical approach to the issue rather than using the option-valuation solution of Stanton and Wallace (2004). The value of the break clauses was found to fall as the time to break period increased. Removing leases from the sample that included a break clause did not affect the outcome of the study.

Finally as a robustness check we estimated the econometric models on a similar data set obtained from Estates Gazette. The finding of an upward sloping term structure to initial lease rates was still evident in this alternative data set. 


\section{References}

Ambrose B. Hendershott, P. and Klosek, M. 2002 Pricing Upward-Only Adjusting Leases, Journal of Real Estate Finance and Economics, 25, 33-49.

Booth P and Walsh D 2001 An option pricing approach to valuing upward only rent review properties with multiple reviews. Insurance: Mathematics and Economics, 28, 151-171.

Booth P and Walsh D 2001b The application of financial theory to the pricing of upward-only rent reviews, Journal of Property Research, 18(1), 69-83.

Englund P, Gunnelin A, Hoesli M and Söderberg B Implicit Forward Rents As Predictors Of Future Rents Aberdeen Papers In Accountancy, Finance \& Management

Grenadier, S.R 1995 The valuation of leasing contracts: a real options approach. Journal of Financial Economics, 38: 297-331.

Gunnelin, $\AA$. and B. Söderberg. 2003. Term Structures in the Office Rental Market in Stockholm. Journal of Real Estate Finance and Economics 26(2/3): 241-265.

Hendershott P and Ward C 2003 Valuing and pricing retail leases with renewal and overage options, Journal of Real Estate Finance and Economics, 26(2/3), 223-240

Miceli T and Sirmans, C. 1995 Contracting with spatial externalities and agency problems: the case of retail leases. Regional Science and Urban Economics, 25, 355-372

McCann, P. and Ward, C. 2003 Real Estate Rental Payments: Application of Stock-Inventory Modelling The Journal of Real Estate Finance and Economics, 28(2).

Mooradian R and Yang, S 2000 Cancellation strategies in commercial real estate leasing, Real Estate Economics, 28, 65-88.

ODPM 2004 Monitoring the code of practice for commercial leases: interim report. The University of Reading, Reading and Office of the Deputy Prime Minister, London.

ODPM, 2005 Monitoring the code of practice for commercial leases: final report. The University of Reading, Reading and Office of the Deputy Prime Minister, London.

Stanton W and Wallace N 2004 An Empirical Test of a Contingent Claims Lease Valuation Model, Working Paper, Haas School of Business U.C. Berkeley.,

Wheaton, W.C. 2000 Percentage rent in retail leasing: the alignment of landlord-tenant interests, Real Estate Economics, 28, 185-204. 


\section{Appendix}

Figure 1.

The Major Segments of the London Office Market

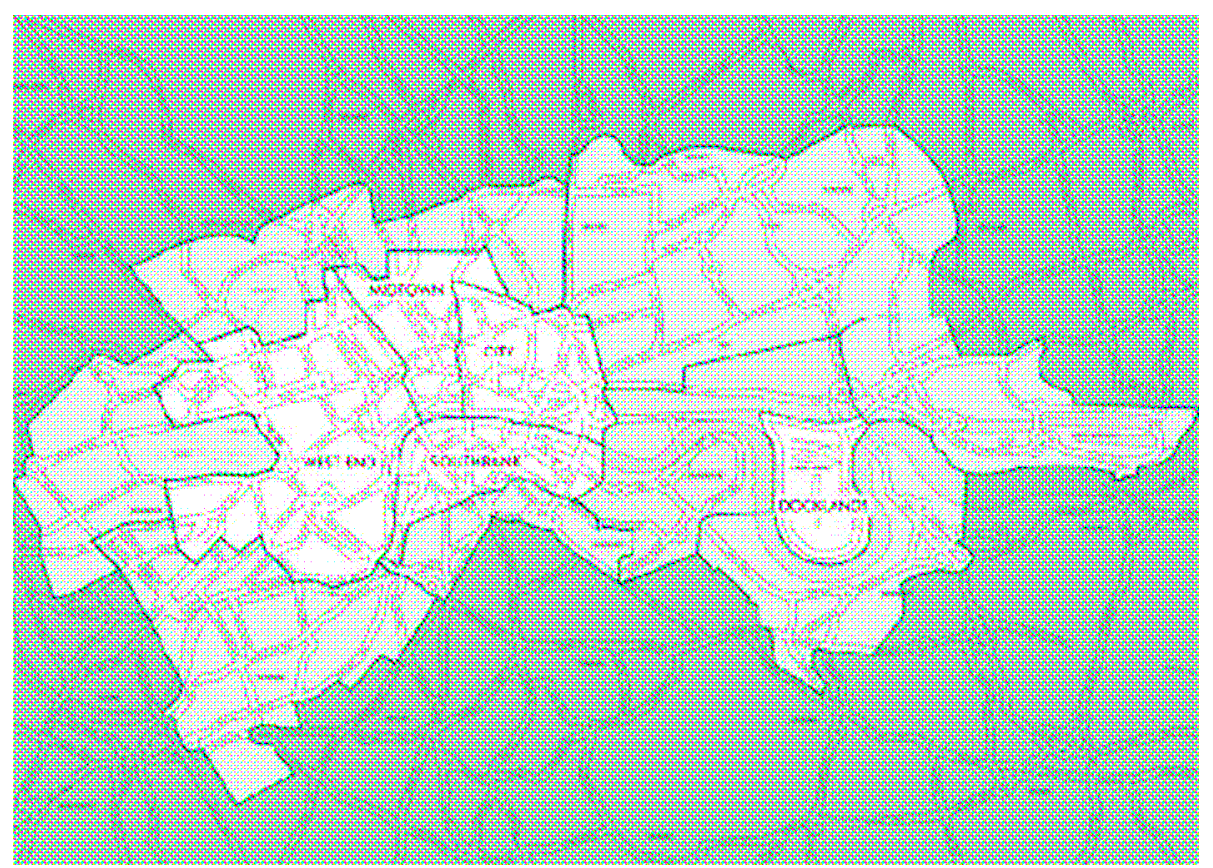

Map provided by CB Richard Ellis. The map displays the key segments, by location, in the London market. The data in this study is primarily focused on the West End and City markets. 
Table 1

Summary Characteristic of Lease Contracts

CBRE Lease Database of Leases over 10, $000 \mathrm{ft}^{2}$

1994 - 2004

\begin{tabular}{lrrr}
\hline & Full Sample & City & West End \\
\hline Rent & 337.34 & 345.09 & 323.77 \\
$\quad$ Std deviation & 144.40 & 141.86 & 147.96 \\
Real Rent & 349.10 & 355.54 & 337.83 \\
$\quad$ Std deviation & 140.82 & 138.34 & 144.58 \\
Size (m2) & $3,088.12$ & $3,506.95$ & 2355.17 \\
$\quad$ Std deviation & $4,504.81$ & $5,231.56$ & 2666.09 \\
Term & 14.03 & 14.47 & 13.28 \\
$\quad$ Std deviation & 5.54 & 5.60 & 5.37 \\
\% Grade A & 59 & 67 & 46 \\
\% Grade B & 26 & 23 & 32 \\
\% Grade C & 15 & 10 & 22 \\
No. of lease breaks & 320 & 225 & 95 \\
\% lease breaks & 34 & 24 & 10 \\
Break length & 8.96 & 9.06 & 8.71 \\
Number & 935 & 595 & 340 \\
\hline \hline
\end{tabular}

Data provided by CBRE. Table contains the summary statistics of the lease contracts in the sample. In addition to reporting the full sampel results the summary statistics are also broken down by area (City and West End). The table reports average initial rent, average real rent, average size and average term of the lease contracts as well as their respective standard deviations. Real rent is the nominal initial rent deflated by the implicit price deflator of domestic final demand. \% Grade A, B \& $\mathrm{C}$ shows the percentage of the sample leases involving the respective grade of property. No. of lease breaks shows how many leases in the sample contain break clauses and \% lease breaks give the respective percentage relative to the total number of leases. Break length is the average term until the breal clause can be exercised for those leases that contain such clauses. Number is the number of leases in each category. 


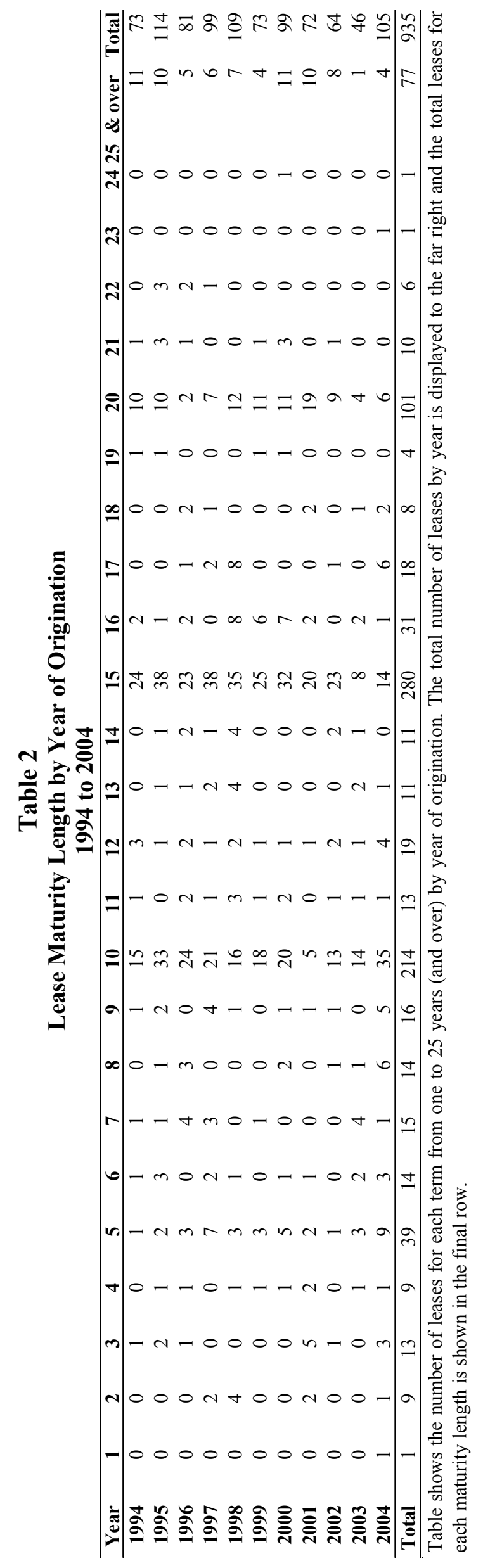




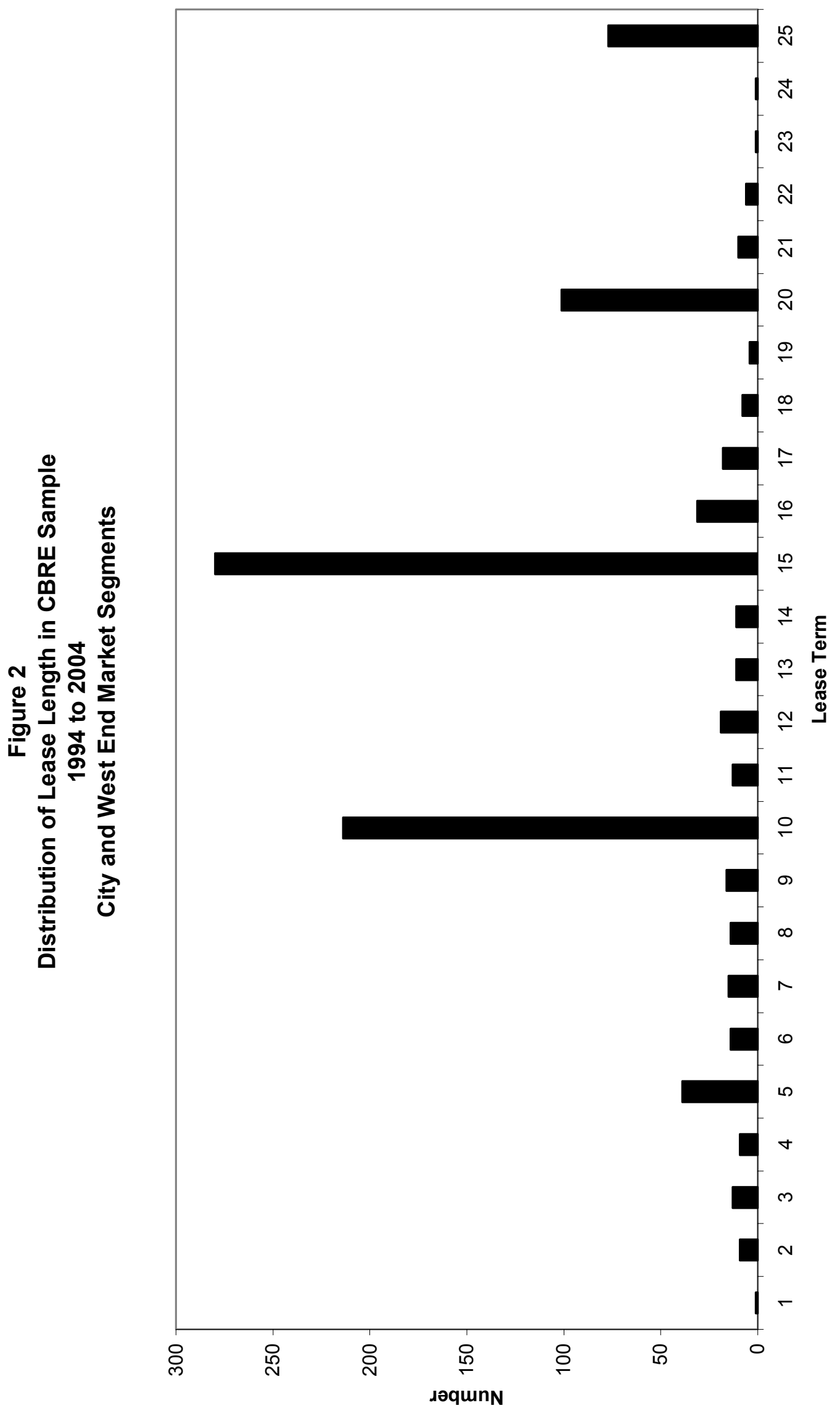


Table 3

Linear Regression Results for Equation (2) London Office Leases, 1994 to 2004.

\begin{tabular}{|c|c|c|c|c|}
\hline \multirow[b]{2}{*}{ Variable } & \multicolumn{3}{|c|}{ Standard } & \multirow{2}{*}{$\begin{array}{r}\text { Prob } \\
>|t|\end{array}$} \\
\hline & Coefficient & Error & t-ratio & \\
\hline CONST & 5.199 & 0.224 & 23.200 & 0.00 \\
\hline LS & -0.057 & 0.016 & -3.481 & 0.00 \\
\hline D95 & -0.089 & 0.229 & -0.389 & 0.70 \\
\hline D96 & 0.248 & 0.249 & 0.994 & 0.32 \\
\hline D97 & 0.248 & 0.222 & 1.118 & 0.26 \\
\hline D98 & 0.301 & 0.227 & 1.326 & 0.19 \\
\hline D99 & 0.486 & 0.250 & 1.942 & 0.05 \\
\hline D00 & 0.480 & 0.211 & 2.274 & 0.02 \\
\hline D01 & 0.591 & 0.267 & 2.210 & 0.03 \\
\hline D02 & 0.885 & 0.244 & 3.625 & 0.00 \\
\hline D03 & 0.183 & 0.351 & 0.522 & 0.60 \\
\hline D04 & -0.133 & 0.243 & -0.549 & 0.58 \\
\hline ТМ94 & 0.023 & 0.010 & 2.300 & 0.02 \\
\hline TM95 & 0.022 & 0.009 & 2.419 & 0.02 \\
\hline TM96 & 0.015 & 0.012 & 1.213 & 0.23 \\
\hline TM97 & 0.023 & 0.008 & 2.993 & 0.00 \\
\hline ТМ98 & 0.033 & 0.008 & 4.115 & 0.00 \\
\hline ТМ99 & 0.034 & 0.010 & 3.508 & 0.00 \\
\hline ТМ00 & 0.035 & 0.006 & 5.438 & 0.00 \\
\hline TM01 & 0.038 & 0.011 & 3.629 & 0.00 \\
\hline ТМ02 & 0.025 & 0.009 & 2.726 & 0.01 \\
\hline TM03 & 0.034 & 0.021 & 1.636 & 0.10 \\
\hline TM04 & 0.039 & 0.010 & 3.792 & 0.00 \\
\hline LBK & -0.033 & 0.014 & -2.310 & 0.02 \\
\hline GRB & -0.197 & 0.038 & -5.251 & 0.00 \\
\hline GRC & -0.418 & 0.050 & -8.318 & 0.00 \\
\hline LOC & 0.268 & 0.034 & 7.807 & 0.00 \\
\hline Total cases: & 935 & lid case & & 935 \\
\hline Total SS: & 344.995 & grees of & edom: & 908 \\
\hline R-squared: & 0.449 & ar-squa & & 0.433 \\
\hline Residual SS: & 190.229 & error o & & 0.458 \\
\hline $\mathrm{F}(26,908):$ & 28.413 & bability & & 0 \\
\hline Durbin-Watson: & 1.702 & & & \\
\hline
\end{tabular}

The results above are derived from applying equation (2) to the CBRE data set. The variable LS is $\ln ($ size), D95 to D04 are dummy variables representing the years 1995 to 2004. Tm94 to TM04 are interactive dummy variables from the year multiplied by the term length. LMK is $\ln$ (break), where break is the length of break for the lease (if it is available). GRB and GRC are dummy variables for $\mathrm{B}$ grade and $\mathrm{C}$ grade properties respectively. LOC is a dummy variable for location which takes the value of 1 for leases in the West End. Variables and parameters highlighted in bold font denotes significance at the $10 \%$ level. 
Table 4

Linear Regression Results for Equation (3) London Office Leases, 1994 to 2004.

\begin{tabular}{|c|c|c|c|c|}
\hline \multirow[b]{2}{*}{ Variable } & \multicolumn{3}{|c|}{ Standard } & \multirow{2}{*}{$\begin{array}{r}\text { Prob } \\
>|t| \\
\end{array}$} \\
\hline & Coefficient & Error & t-ratio & \\
\hline CONST & 4.763 & 0.535 & 8.901 & 0.00 \\
\hline LS & -0.052 & 0.017 & -3.079 & 0.00 \\
\hline D95 & 0.330 & 0.600 & 0.551 & 0.58 \\
\hline D96 & 0.672 & 0.650 & 1.033 & 0.30 \\
\hline D97 & 0.583 & 0.570 & 1.024 & 0.31 \\
\hline D98 & 0.867 & 0.574 & 1.512 & 0.13 \\
\hline D99 & 1.344 & 0.592 & 2.270 & 0.02 \\
\hline D00 & 0.795 & 0.603 & 1.319 & 0.19 \\
\hline D01 & 0.597 & 0.607 & 0.984 & 0.33 \\
\hline D02 & 0.810 & 0.666 & 1.218 & 0.22 \\
\hline D03 & 0.071 & 0.870 & 0.081 & 0.94 \\
\hline D04 & -0.051 & 0.614 & -0.083 & 0.93 \\
\hline TM94 & 0.078 & 0.065 & 1.211 & 0.23 \\
\hline TM95 & 0.018 & 0.036 & 0.519 & 0.60 \\
\hline TM96 & 0.011 & 0.052 & 0.207 & 0.84 \\
\hline TM97 & 0.033 & 0.028 & 1.178 & 0.24 \\
\hline TM98 & 0.005 & 0.028 & 0.177 & 0.86 \\
\hline TM99 & -0.036 & 0.033 & -1.084 & 0.28 \\
\hline TM00 & 0.047 & 0.035 & 1.359 & 0.17 \\
\hline ТМ01 & 0.112 & 0.034 & 3.319 & 0.00 \\
\hline TM02 & 0.092 & 0.048 & 1.911 & 0.06 \\
\hline TM03 & 0.125 & 0.099 & 1.257 & 0.21 \\
\hline TM04 & 0.098 & 0.046 & 2.159 & 0.03 \\
\hline TM94_2 & -0.002 & 0.002 & -0.933 & 0.35 \\
\hline TM95_2 & 0.000 & 0.001 & 0.088 & 0.93 \\
\hline TM96_2 & 0.000 & 0.002 & 0.069 & 0.95 \\
\hline TM97_2 & 0.000 & 0.001 & -0.414 & 0.68 \\
\hline TM98_2 & 0.001 & 0.001 & 1.104 & 0.27 \\
\hline TM99_2 & 0.002 & 0.001 & 2.238 & 0.03 \\
\hline TM00_2 & 0.000 & 0.001 & -0.420 & 0.67 \\
\hline TM01_2 & -0.003 & 0.001 & -2.752 & 0.01 \\
\hline TM02_2 & -0.002 & 0.001 & -1.549 & 0.12 \\
\hline TM03_2 & -0.003 & 0.003 & -1.052 & 0.29 \\
\hline TM04_2 & -0.002 & 0.002 & -1.471 & 0.14 \\
\hline TM03_2 & -0.003 & 0.003 & -1.033 & 0.30 \\
\hline TM04_2 & -0.002 & 0.002 & -1.468 & 0.14 \\
\hline LBK & -0.032 & 0.014 & -2.234 & 0.03 \\
\hline GRB & -0.199 & 0.038 & -5.289 & 0.00 \\
\hline GRC & -0.411 & 0.050 & -8.272 & 0.00 \\
\hline LOC & 0.266 & 0.034 & 7.828 & 0.00 \\
\hline Total cases: & 935 & lid case & & 935 \\
\hline Total SS: & 344.995 & grees of & edom: & 897 \\
\hline R-squared: & 0.46 & ar-squa & & 0.437 \\
\hline Residual SS: & 186.455 & error o & & 0.456 \\
\hline $\mathrm{F}(37,897):$ & 20.614 & bability & & 0 \\
\hline Durbin-Watson: & 1.708 & & & \\
\hline
\end{tabular}

The results above are derived from applying equation (3) to the CBRE data set. The variable LS is $\ln$ (size), D95 to D04 are dummy variables representing the years 1995 to 2004 . Tm94 to TM04 are interactive dummy variables from the year multiplied by the term length. TM94 2 to TM04 2 represents the square of the interative lease term. LMK is $\ln$ (break), where break is the length of break for the lease (if it is available). GRB and GRC are dummy variables for B grade and $\mathrm{C}$ grade properties respectively. LOC is a dummy variable for location which takes the value of 1 for leases in the West End. Variables and parameters highlighted in bold font denotes significance at the $10 \%$ level. 
Table 5

Linear Regression Results Initial Rent

London Office Leases, 1994 to 2004.

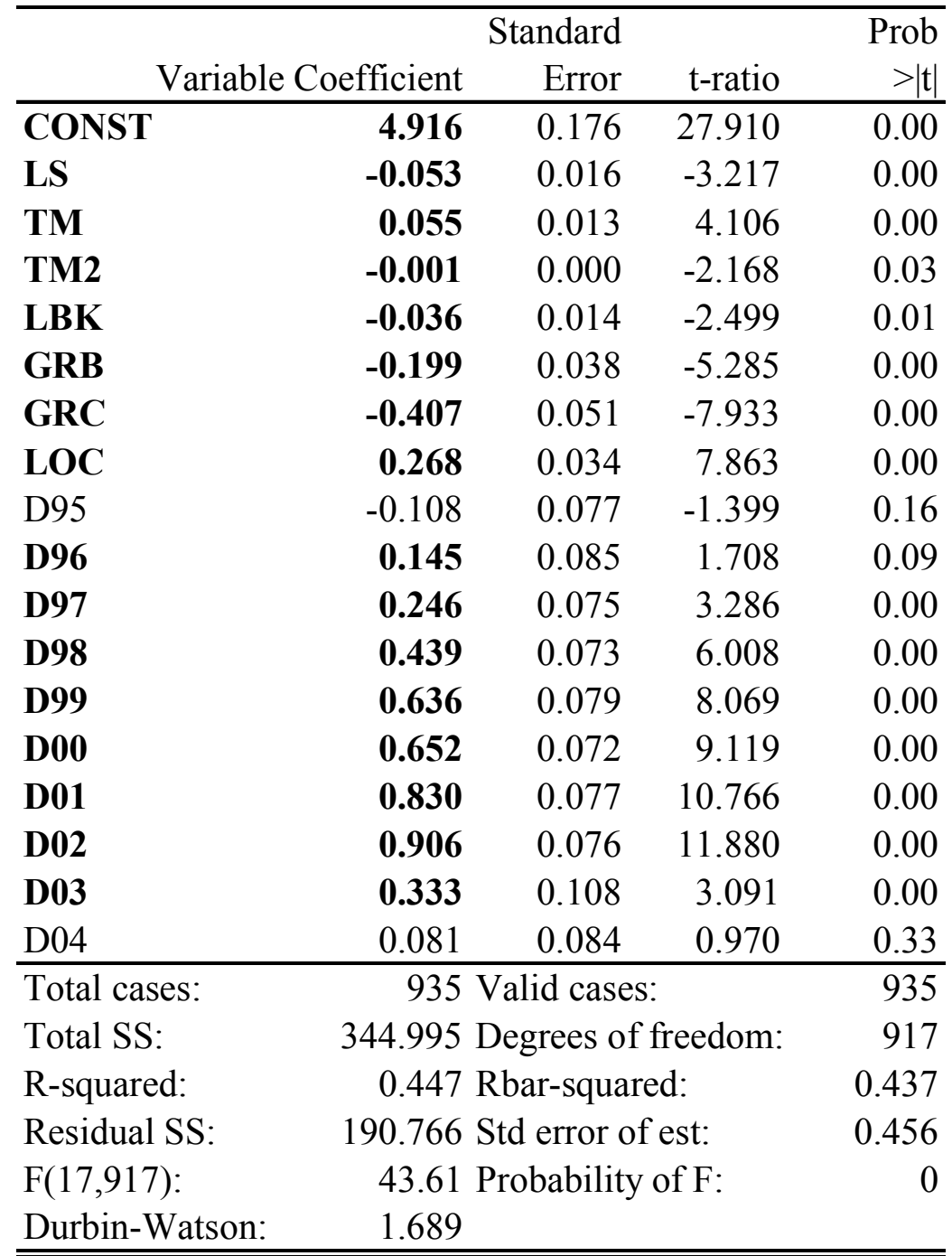

The results above are derived from applying equation (2) to the CBRE data set. The variable LS is $\ln$ (size), D95 to D04 are dummy variables representing the years 1995 to 2004 . TM is the term of the lease and TM2 is the square of term of the lease length. LMK is $\ln ($ break), where break is the length of break for the lease (if it is available). GRB and GRC are dummy variables for $\mathrm{B}$ grade and $\mathrm{C}$ grade properties respectively. LOC is a dummy variable for location which takes the value of 1 for leases in the West End. Variables and parameters highlighted in bold font denotes significance at the $10 \%$ level. 
Table 6

Linear Regression Results Initial Rent

London Office Leases, 1994 to 2004.

\begin{tabular}{|c|c|c|c|c|}
\hline \multirow[b]{2}{*}{ Variable } & \multicolumn{3}{|c|}{ Standard } & \multirow{2}{*}{$\begin{array}{r}\text { Prob } \\
>|t|\end{array}$} \\
\hline & Coefficient & Error & t-ratio & \\
\hline CONST & 5.071 & 0.186 & 27.233 & 0.00 \\
\hline D95 & -0.109 & 0.078 & -1.407 & 0.16 \\
\hline D96 & 0.151 & 0.085 & 1.769 & 0.08 \\
\hline D97 & 0.245 & 0.075 & 3.261 & 0.00 \\
\hline D98 & 0.453 & 0.074 & 6.144 & 0.00 \\
\hline D99 & 0.641 & 0.079 & 8.106 & 0.00 \\
\hline D00 & 0.659 & 0.072 & 9.171 & 0.00 \\
\hline D01 & 0.913 & 0.073 & 12.531 & 0.00 \\
\hline D02 & 0.932 & 0.076 & 12.278 & 0.00 \\
\hline D03 & 0.359 & 0.106 & 3.377 & 0.00 \\
\hline D04 & 0.104 & 0.083 & 1.243 & 0.21 \\
\hline $\mathbf{L S}$ & -0.054 & 0.016 & -3.310 & 0.00 \\
\hline TM & 0.036 & 0.016 & 2.292 & 0.02 \\
\hline TM2 & 0.000 & 0.000 & -0.752 & 0.45 \\
\hline LBK & -0.034 & 0.014 & -2.407 & 0.02 \\
\hline GRB & -0.214 & 0.037 & -5.748 & 0.00 \\
\hline GRC & -0.407 & 0.050 & -8.079 & 0.00 \\
\hline LOC & 0.266 & 0.034 & 7.898 & 0.00 \\
\hline Total cases: & 903 & lid case & & 903 \\
\hline Total SS: & 317.822 & grees of & eedom: & 885 \\
\hline R-squared: & 0.453 & ar-squal & & 0.442 \\
\hline Residual SS: & 173.88 & error o & & 0.443 \\
\hline $\mathrm{F}(17,885):$ & 43.095 & bability & $f F:$ & 0 \\
\hline Durbin-Watson: & 1.692 & & & \\
\hline
\end{tabular}

The results above are derived from a version of equation (2) to the CBRE data set. The variable LS is $\ln ($ size), D95 to D04 are dummy variables representing the years 1995 to 2004 . TM is the term of the lease and TM2 is the square of term of the lease length. LMK is $\ln ($ break), where break is the length of break for the lease (if it is available). GRB and GRC are dummy variables for $\mathrm{B}$ grade and $\mathrm{C}$ grade properties respectively. LOC is a dummy variable for location which takes the value of 1 for leases in the West End. Variables and parameters highlighted in bold font denotes significance at the $10 \%$ level. Note that in this dataset all leases with a term below five years have been removed. 


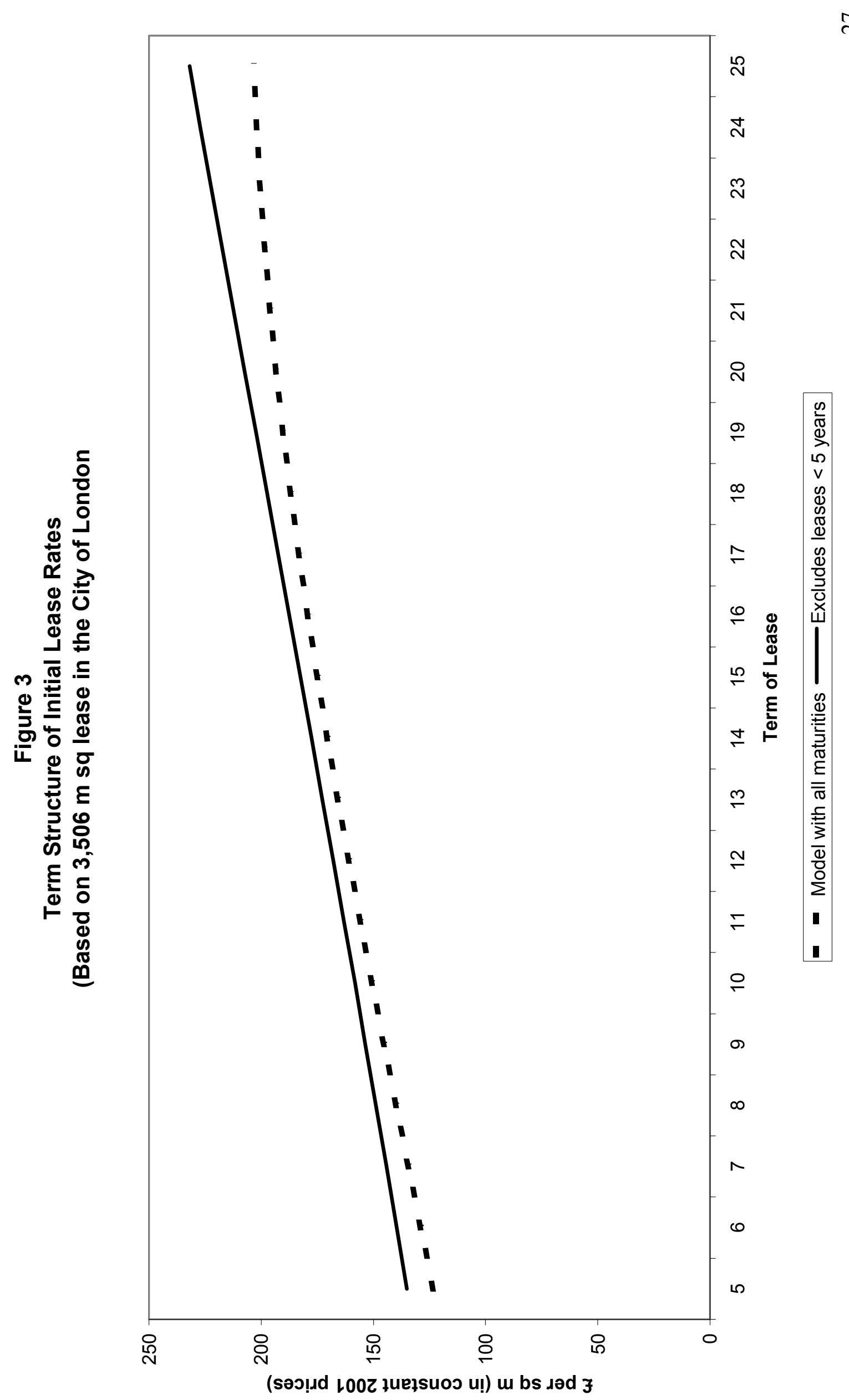

